\title{
Simulating the Aerodynamic Heating of Gun-Launched Projectiles in Hypersonic Applications
}

\author{
Hatem H. Daken *
}

\begin{abstract}
A model was designed and built using The Mathworks' SIMULINK to simulate the aerodynamic heating of gun-launched projectiles ballistically flying at hypersonic velocities in the lower and upper atmosphere. The model is based on NASA Ames real-time aerodynamic heating and surface temperature calculations for hypersonic flight simulation. Developed model was used to predict the stagnation and surface temperatures of three conceptual projectiles intended for use as Navy Area Theater Ballistic Missile Defense (NATBMD) training targets.
\end{abstract}

Keywords: SIMULINK, Exterior Ballistics, Hypersonic Flight, Aerodynamic Heating, NATBMD

\section{Introduction}

The U.S. Navy's Naval Surface Fire Support Systems (NSFS) Program Office PMS 529, which is currently reorganized into the Program Executive Office (PEO) for Integrated Warfare Systems (IWS) Code PEO IWS 3C, has developed visionary objectives for using 8" shipboard gun-launched projectiles to provide navy area theater ballistic missile defense (NATBMD) low fidelity training targets for naval groups, bases, and neighboring strategic targets as part of its SBIR (Small Business Innovation Research) program.

Validation of these objectives required the evaluation of candidate projectiles, materials, and sensor technologies. Preliminary evaluation of three conceptual projectiles weighing 100, 150, and $200 \mathrm{~kg}$, Figure 1, having the same muzzle exit energy of $500 \mathrm{MJ}$ (Mega Joules), resulted in predicted maximum Mach numbers of 9.9, 8.2, and 7.1, respectively. As shown in Figure 2 these projectiles are flying at or above Mach 3 for an average of $45 \%$ of their total flight time. At such flight speeds aerodynamic heating becomes a major concern that has to be addressed as it impacts the choice of airframe structural materials and sensors needed for target identification, acquisition, and tracking. Determining the thermal exposure of these projectiles through their entire flight trajectory is necessary to determine the temperature knock-down factors used to compute the degraded mechanical properties of the materials selected for their structures at such high temperatures. Figure 3 indicates that the flight Mach numbers start to drop sharply as the projectiles enter into the upper atmosphere, mainly because the speed of sound increases sharply between the altitudes of 100 to $500 \mathrm{~km}$. Most of the aerodynamic heating and the rise in the projectile's nose and skin temperatures occurs within the lower atmosphere.

\footnotetext{
Ph.D., Senior Structural Analysis Scientist/Engineer, Boeing Commercial Airplanes, The Boeing Company, Seattle, WA, USA (work was performed while working as the Principal Engineer, Defense Technology Inc., DTI, Arlington, VA, USA), hatemdaken@aol.com 
The aerodynamic heating model adopted for implementation with the 3DOF exterior ballistics model is NASA Ames Real-Time Aerodynamic Heating and Surface Temperature Calculations for Hypersonic Flight Simulation ${ }^{1,2}$. This model is a FORTRAN 77 based code that can calculate two and three-dimensional stagnation point and surface heating rates and temperatures. The two-dimensional calculations can be made with or without leading edge sweep. In addition, upper and lower surface heating rates and temperatures for flat plates, wedges, and cones can be calculated, with boundary layer transition made as a function of the free stream Reynolds and Mach numbers.

\section{Description of Model Key Elements}

We used MATLAB's SIMULINK version 5.0.1 to develop our aerodynamic heating model. Given that NASA's model is entirely based on the use of English units, conversion blocks and switches were introduced to ensure unit compatibility between the outputs of the atmosphere and exterior ballistics modules, which employ SI units, and the inputs of the aerodynamic heating module. The model is comprised from the following modules:

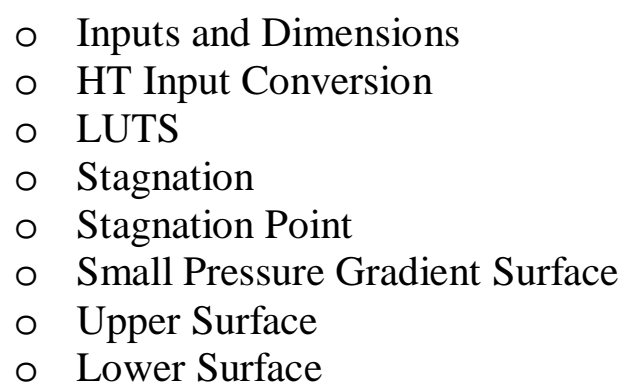

This model does not require any DO loops and all variables are handled as scalars. It provides the capability to compute the variation in stagnation and surface temperatures and heating rates, at any given point, with speed, altitude, angle of attack, leading edge sweep and shape, flow dimensions, and heat capacities and emissivities of used structural materials. The building blocks illustrated in Figures 11 through 23 at the end of this article represent the general architecture and layout of this model. Including all the layers and details in this article was not possible because of space limitations. Equations of the NASA Ames Real Time Aerodynamic Heating model can be found in Reference [1].

\section{Inputs and Dimensions}

Permits the user to choose flow dimensions of the problem and leading edge shape and input the initial temperature, material properties of the nose and skin, leading edge sweep, angle of attack, and wedge or cone angles. It also allows the user to choose the units of input values and perform any needed unit conversion to English units.

\section{HT Input Conversion}

Converts atmospheric parameters to English units, computes the free stream velocity (U_inf) and viscosity (Mu_inf), computes the upper and lower surface angles (Surf) and limits their values to applicable range, and sets the leading edge sweep (Lambda) to 0 in case of 3D or conical flow. 


\section{LUTS (Look Up Tables)}

This module is used to look up the transition Mach number coefficient (C_m) and determine the flow type (laminar $=1$, turbulent $=0$ ) at the point of measurement $(\mathrm{POM})$. It also looks up the flow correction factor $\left(\mathrm{A}_{-} \mathrm{i}\right)$, the stagnation heating factor $\left(\mathrm{K}_{-} \mathrm{i}\right)$, and the free stream enthalpy (H_inf).

\section{Stagnation and Stagnation Point}

The stagnation module computes stagnation enthalpy (H_st), stagnation pressure (P_st), and the local heat transfer coefficient (h) at the stagnation point. The stagnation point module computes stagnation temperature (T_w_S ) by integrating the stagnation heating rate.

\section{SPGS (Small Pressure Gradient Surface)}

Computes the reference enthalpy (H_R) and the local heat transfer coefficients of the upper and lower surfaces, (h_U) and (h_L), at the point of measurement.

\section{US (Upper Surface) and LS (Lower Surface)}

These modules compute the upper surface temperature (T_w_U) and lower surface temperature (T_w_L) at the point of measurement by integrating the local heating rate

\section{Model Initialization, Validation, and Results}

\section{Initialization}

Parameters that need to be entered manually, or selected from predetermined values, are:

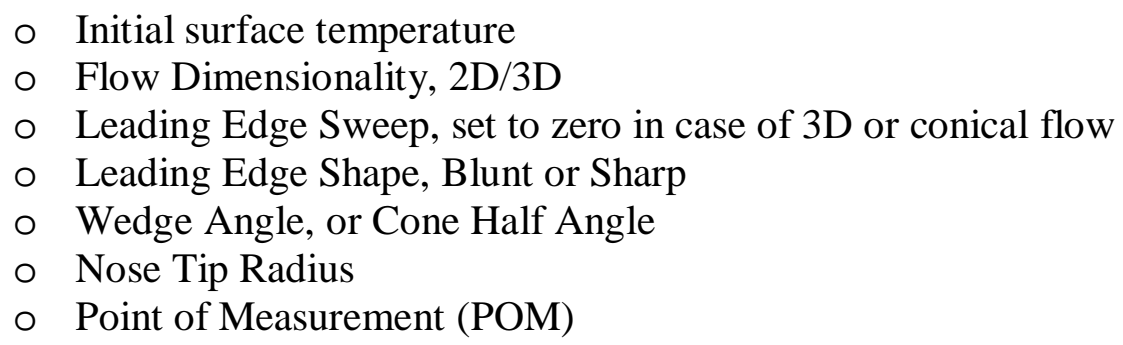

The following parameters are entered for both the nose and skin materials and are used to calculate their heat capacities:

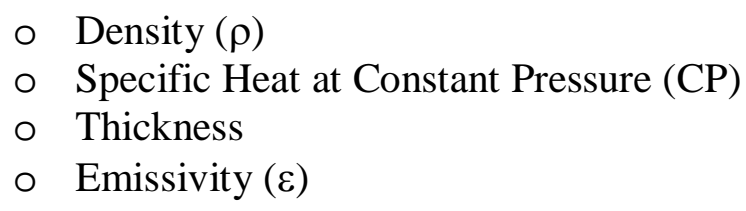

Parameters that could be either entered manually or automatically read from the system are:

○ Angle of Attack $(\alpha)$

Parameters that are automatically read from the atmosphere and exterior ballistics modules are free stream:
○ Velocity (U_inf)
- Temperature (T_inf)
- Pressure (P_inf)
- Density (Rho_inf)
○ Mach number (M_inf) 


\section{Validation}

The model was validated by running the generic hypersonic vehicle data provided by NASA in reference [1]. This data set is in the form of charts depicting the change in velocity, altitude, and angle of attack of this vehicle versus time. These charts had to be digitized to provide the digital input needed for running DTI's model.

\section{Results}

The following table summarizes the data used to simulate the aerodynamic heating of the three conceptual ballistic missile defense (BMD) training targets.

Table 1: Aerodynamic Heating Simulation Parameters

\begin{tabular}{|c|c|c|c|c|c|c|c|c|c|c|c|c|c|c|}
\hline \multirow{3}{*}{$\begin{array}{l}\text { Projectile } \\
\text { Code }\end{array}$} & \multicolumn{4}{|c|}{ Projectile Parameters } & \multicolumn{4}{|c|}{$\begin{array}{c}\text { Cone Tip } \\
\text { Parameters }\end{array}$} & \multicolumn{6}{|c|}{$\begin{array}{c}\text { Launch \& Flight } \\
\text { Parameters }\end{array}$} \\
\hline & 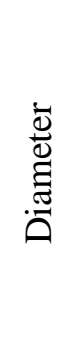 & 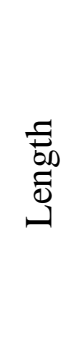 & $\begin{array}{l}\frac{\overrightarrow{0}}{60} \\
\frac{0}{0} \\
3\end{array}$ & 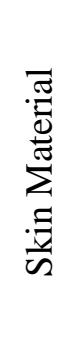 & 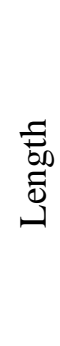 & 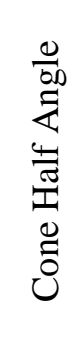 & 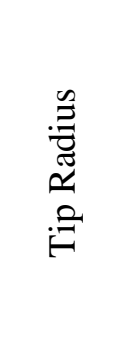 & 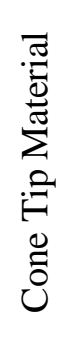 & 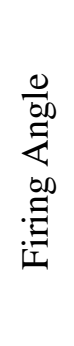 & 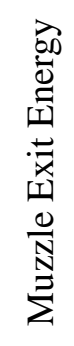 & 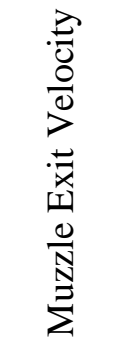 & 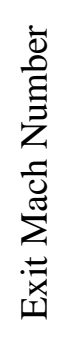 & 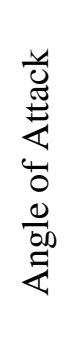 & 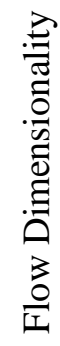 \\
\hline & in & $\mathrm{ft}$ & $\mathrm{kg}$ & -- & in & deg & in & -- & deg & MJ & $\mathrm{m} / \mathrm{sec}$ & 1 & deg & -- \\
\hline $\begin{array}{l}\text { 8"/6 Calib. } \\
\text { 8"/9 Calib. } \\
\text { 8"/12 Calib. }\end{array}$ & 8 & 4 & $\begin{array}{l}100 \\
150 \\
200\end{array}$ & 峦 & 5 & 5.56 & $\begin{array}{l}0.55 \\
\text { (Blunt) }\end{array}$ & 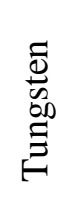 & 64 & 500 & $\begin{array}{l}3162 \\
2582 \\
2236\end{array}$ & $\begin{array}{l}9.3 \\
7.6 \\
6.6\end{array}$ & 0 & $3 \mathrm{D}$ \\
\hline
\end{tabular}

The total flight time of the $8 \% / 6$ calibers-100kg projectile was 535 seconds. It spent approximately 70 seconds in the lower atmosphere while ascending and descending, i.e. $13 \%$ of its total flight time. The $8 " / 9$ calibers-150kg projectile was in its trajectory for 443 seconds from launch to land. It spent approximately 85 seconds in the lower atmosphere, or $19 \%$ of its total flight time. The $8 \% / 12$ calibers-200kg projectile was up for 387 seconds. It spent approximately 104 seconds in the lower atmosphere, or $27 \%$ of its total flight time.

Figure 4 is a comparison between the stagnation temperatures at the tungsten cone tips of the projectiles, Figures 5 and 6 are a comparison between their upper and lower surface temperatures after the end of the tungsten cone tip, Figures 7 and 8 are a comparison between their upper and lower surface temperatures at 36" from the cone tip, and Figures 9 and 10 are a comparison between their upper and lower surface temperatures at their tail. The distance from the cone tip to the tail varies from one projectile to another as seen from the above table.

The heat capacity of the tungsten cone tip is $0.5039 \mathrm{Btu} / \mathrm{ft}^{2}{ }^{\circ} \mathrm{R}$ while that of the projectile's aluminum skin is $0.2661 \mathrm{Btu} / \mathrm{ft}^{2}{ }^{\circ} \mathrm{R}$. This causes the skin material heating rates to be approximately twice the heating rates of the cone tip material at the same location because the heating rate is inversely proportional to the heat capacity. This fact is evident from the above figures. 


\section{Conclusions}

DTI's model agreed very well with the stagnation and surface heating rates and temperatures predicted by NASA's model. Differences are mainly attributed to the difference in accuracy between the FORTRAN 77 code and the SIMULINK model. It is also, in small part, attributed to the digitization accuracy of the generic hypersonic vehicle charts. The trend lines of these charts were thick enough to make any high accuracy digitization process quite impossible. The model accurately predicted the stagnation and surface temperatures of the conceptual projectiles through their entire flight. Using a three degree of freedom (3DOF) exterior ballistics module for this analysis was quite adequate. The use of a six degree of freedom (6DOF) exterior ballistics module was deemed unnecessary. Coupled with the atmosphere and the aerodynamic heating modules it would have strained the simulation engine and might have resulted in unreliable data.

The main objective of this work was not to understand the aerodynamic heating phenomenon and the multitude of factors affecting it. Rather, our objective was to predict the impact of this phenomenon on the structural material choices and sensor technologies available for the three conceptual NATBMD training targets. We could safely claim that DTI's implementation is an honest abstraction of NASA Ames Real Time Aerodynamic Heating for Hypersonic Flight Simulation.

\section{References}

[1] Quinn, R. D. and Gong, L., "Real Time Aerodynamic Heating and Surface Temperature Calculations for Hypersonic Flight Simulation," NASA TM-4222, Washington, DC, 1990, http://www.nasa.gov/centers/dryden/pdf/88193main H-1602.pdf.

[2] Quinn, R. D. and Gong, L., "A Method for Calculating Transient Surface Temperatures and Surface Heating Rates for High-Speed Aircraft," NASA TP-209034, Washington, DC, 2000, http://www.nasa.gov/centers/dryden/pdf/88700main H-2427.pdf.

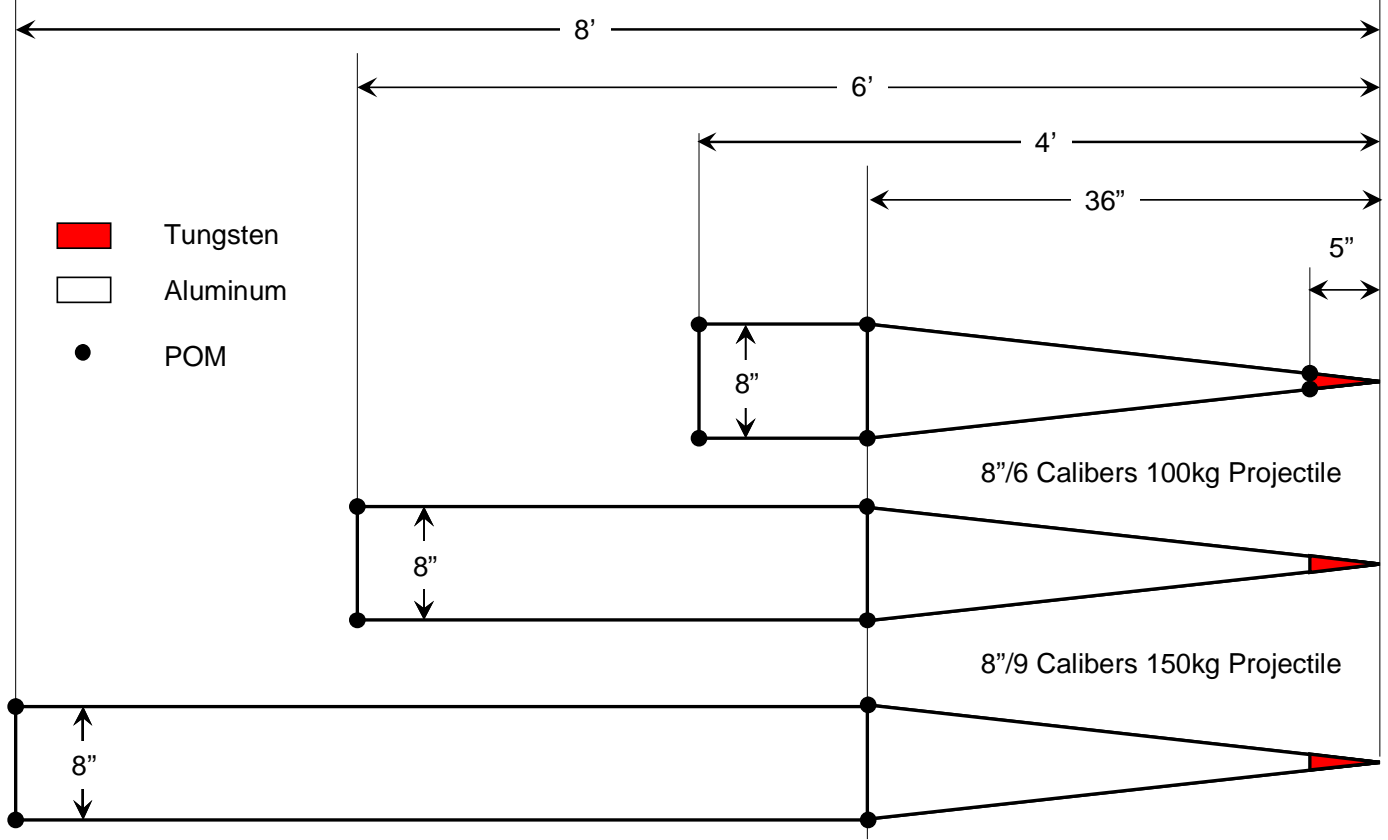

8"/12 Calibers 200kg Projectile

Figure 1: Geometry, Dimensions, Materials, and Points of Measurement (POM) of the Aerodynamic Heating of the Ballistic Missile Defense (BDM) Training Targets 


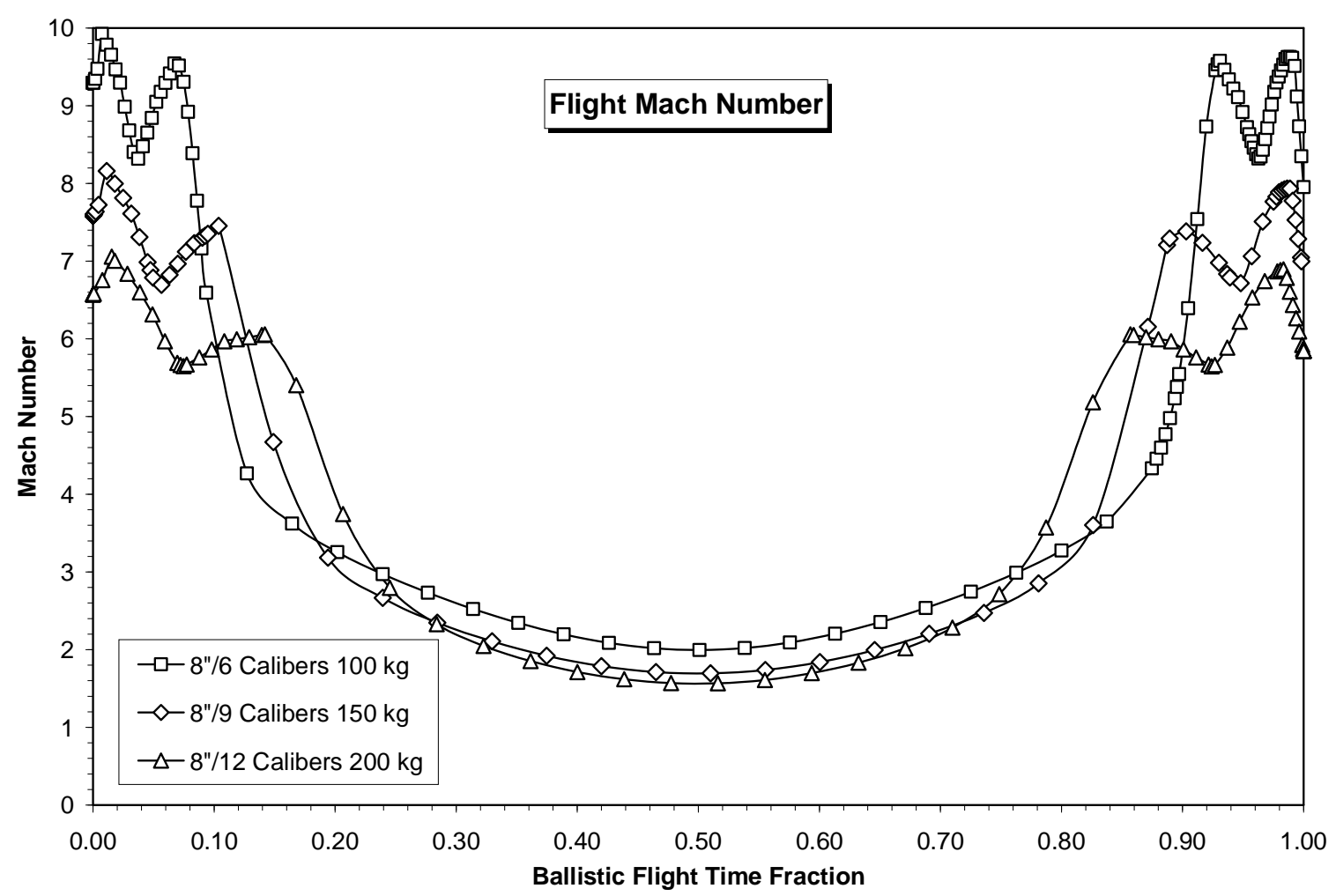

Figure 2: Flight Mach Numbers versus the Ballistic Flight Time Fraction

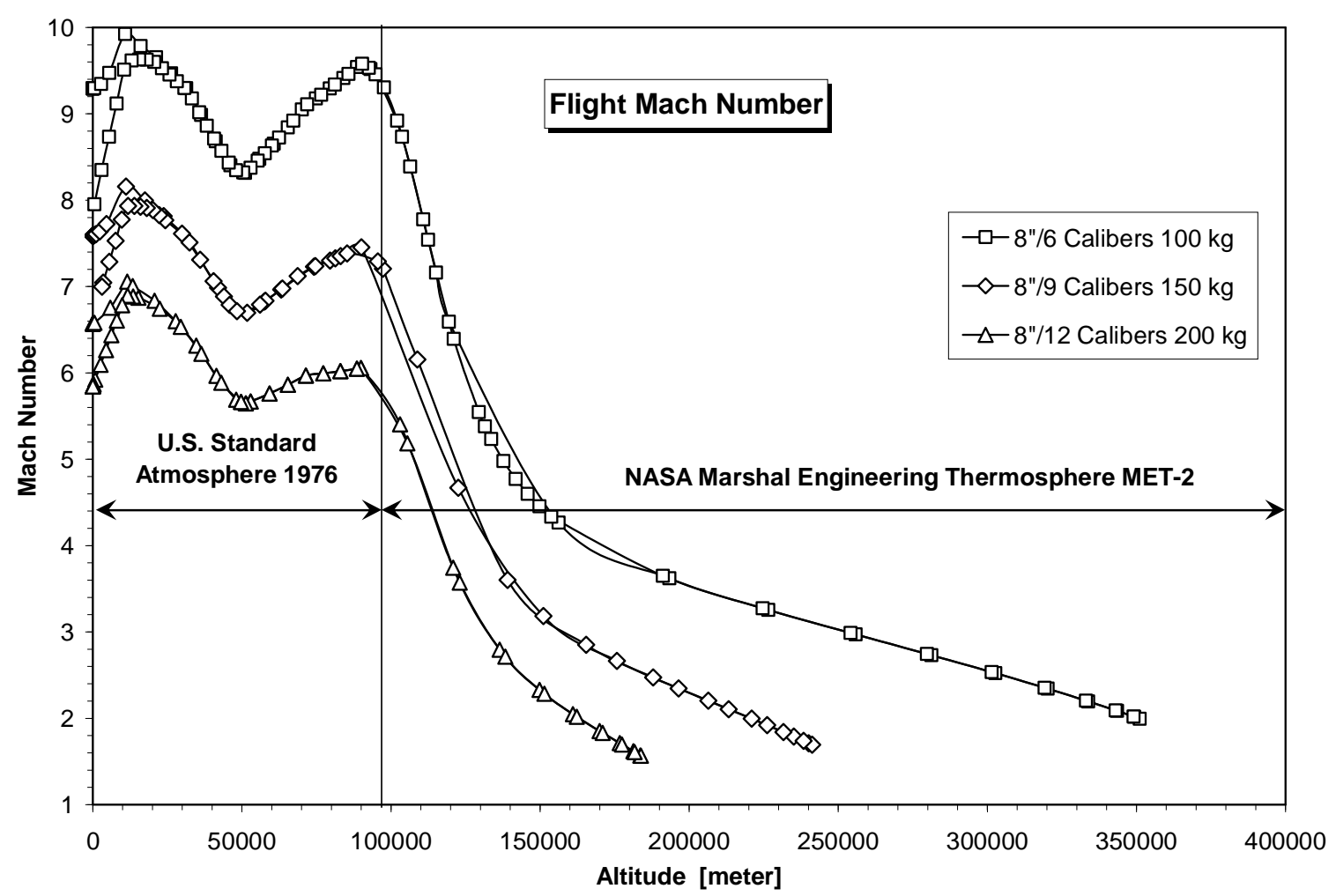

Figure 3: Flight Mach Numbers versus Altitude

(The two pronounced branches per projectile on the left represent the difference between the ascending and descending Mach numbers) 


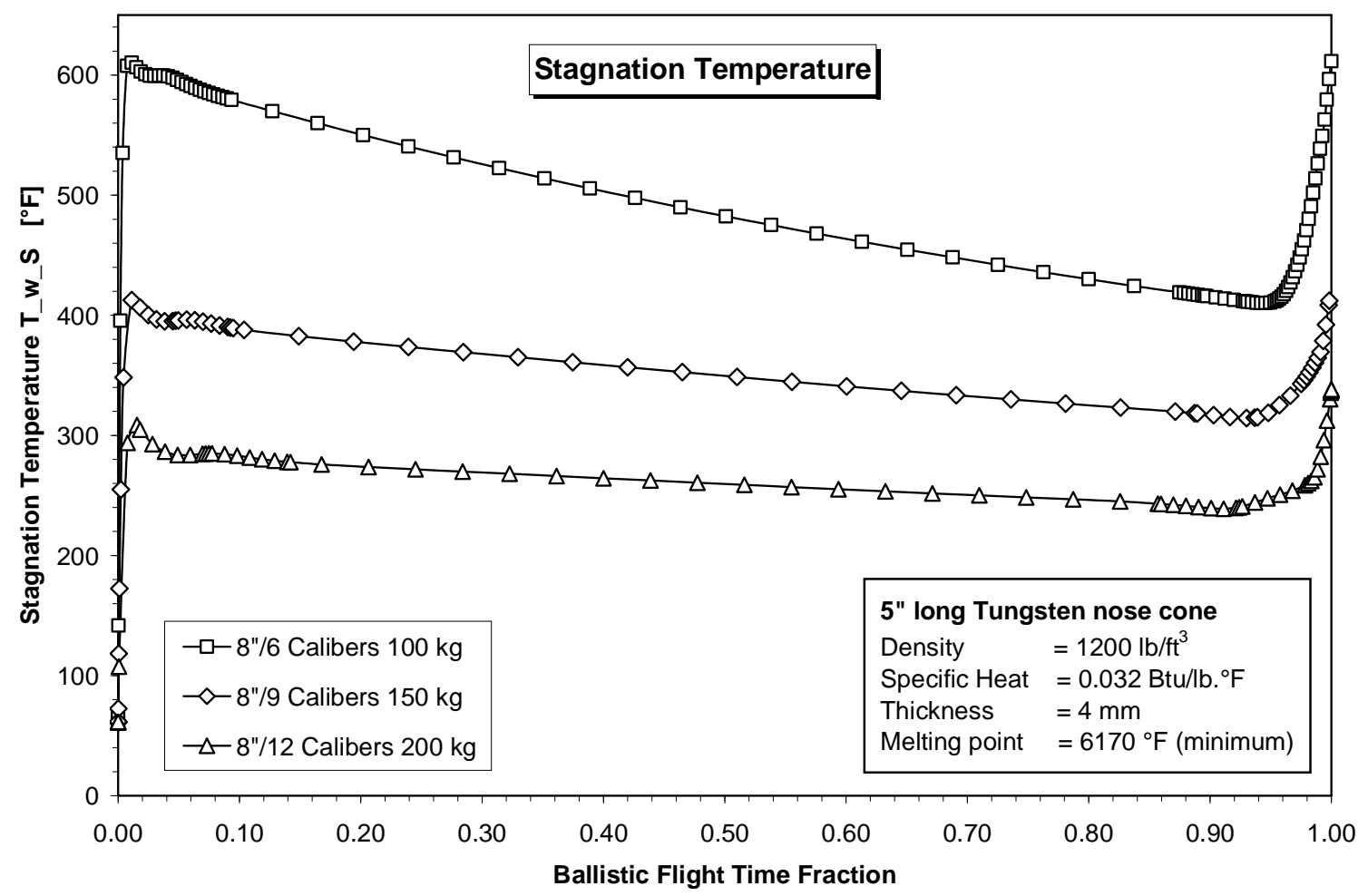

Figure 4: Comparison of the Stagnation Temperatures at the Cone Tip

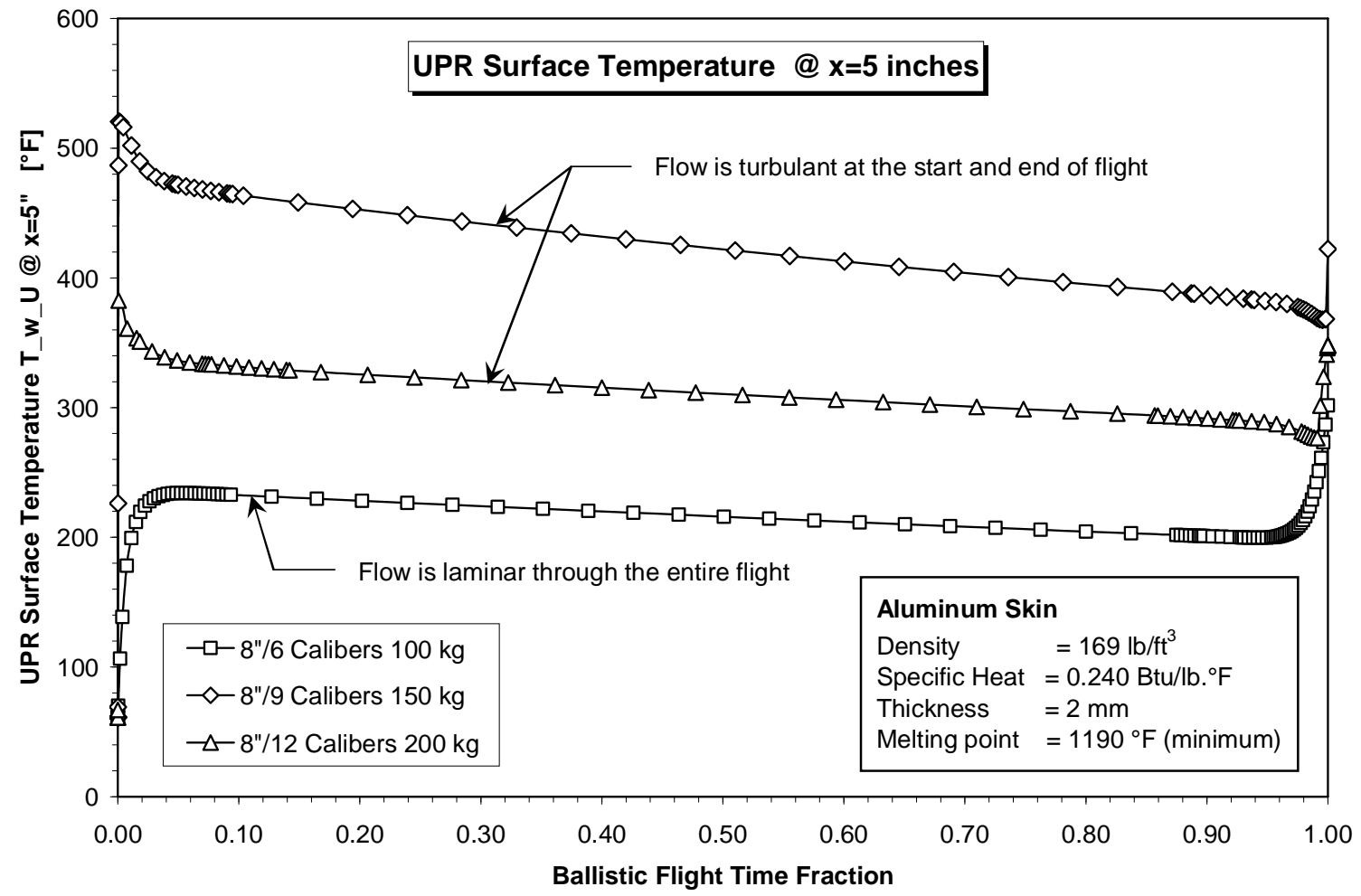

Figure 5: Comparison of the Upper Surface Temperatures at 5 inches from the Cone Tip 


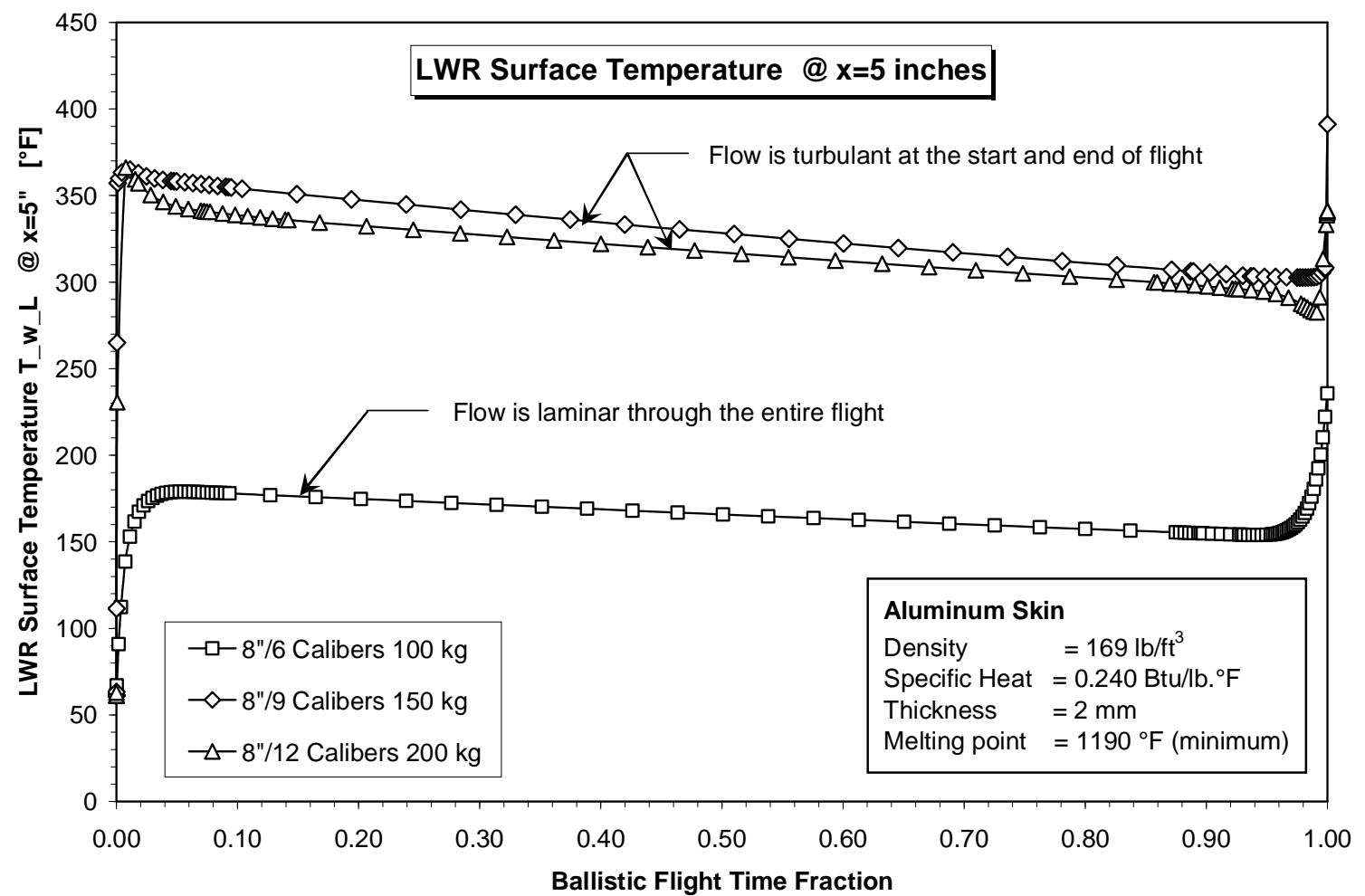

Figure 6: Comparison of the Lower Surface Temperatures at 5 inches from the Cone Tip

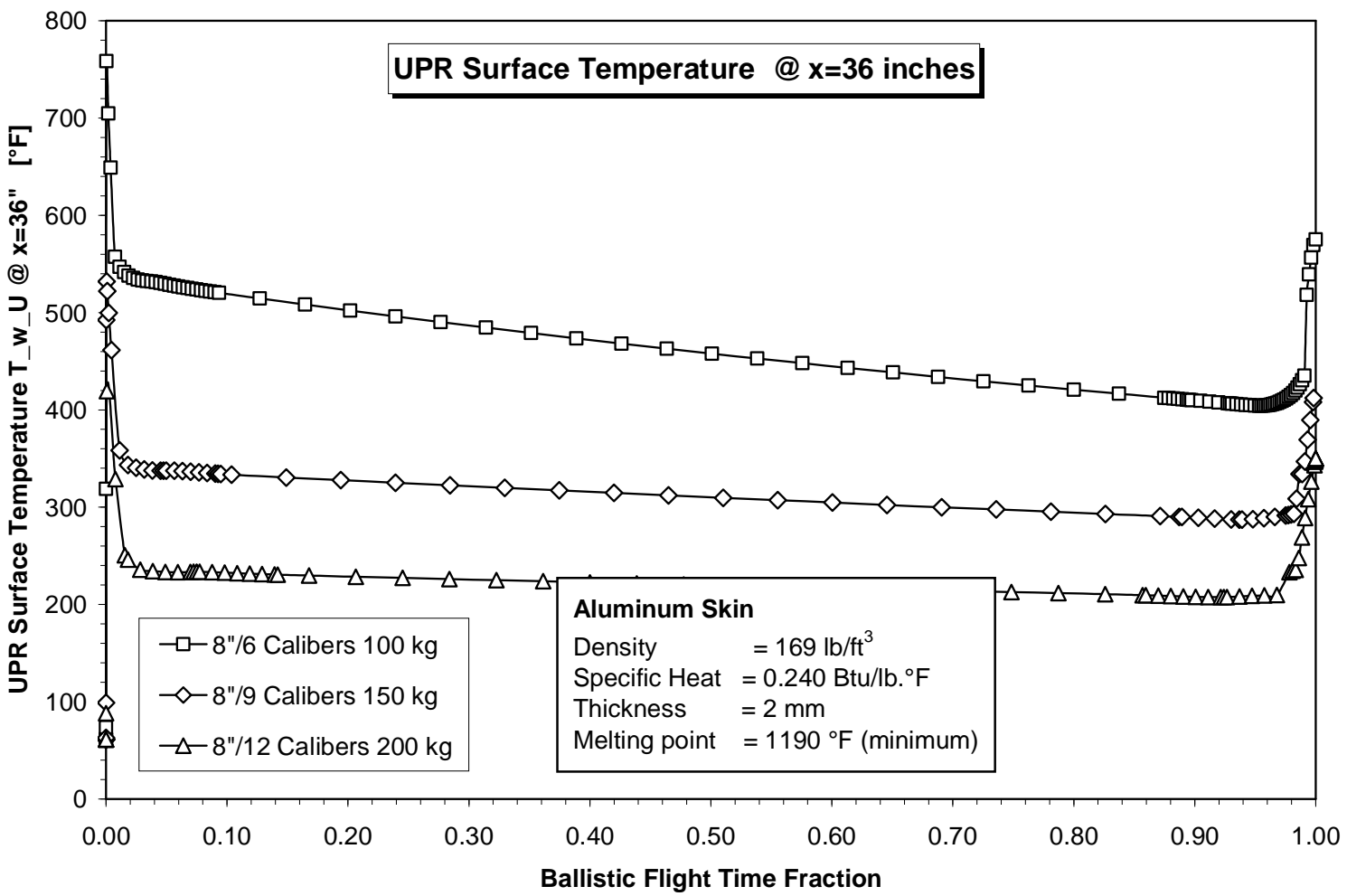

Figure 7: Comparison of the Upper Surface Temperatures at 36 inches from the Cone Tip 


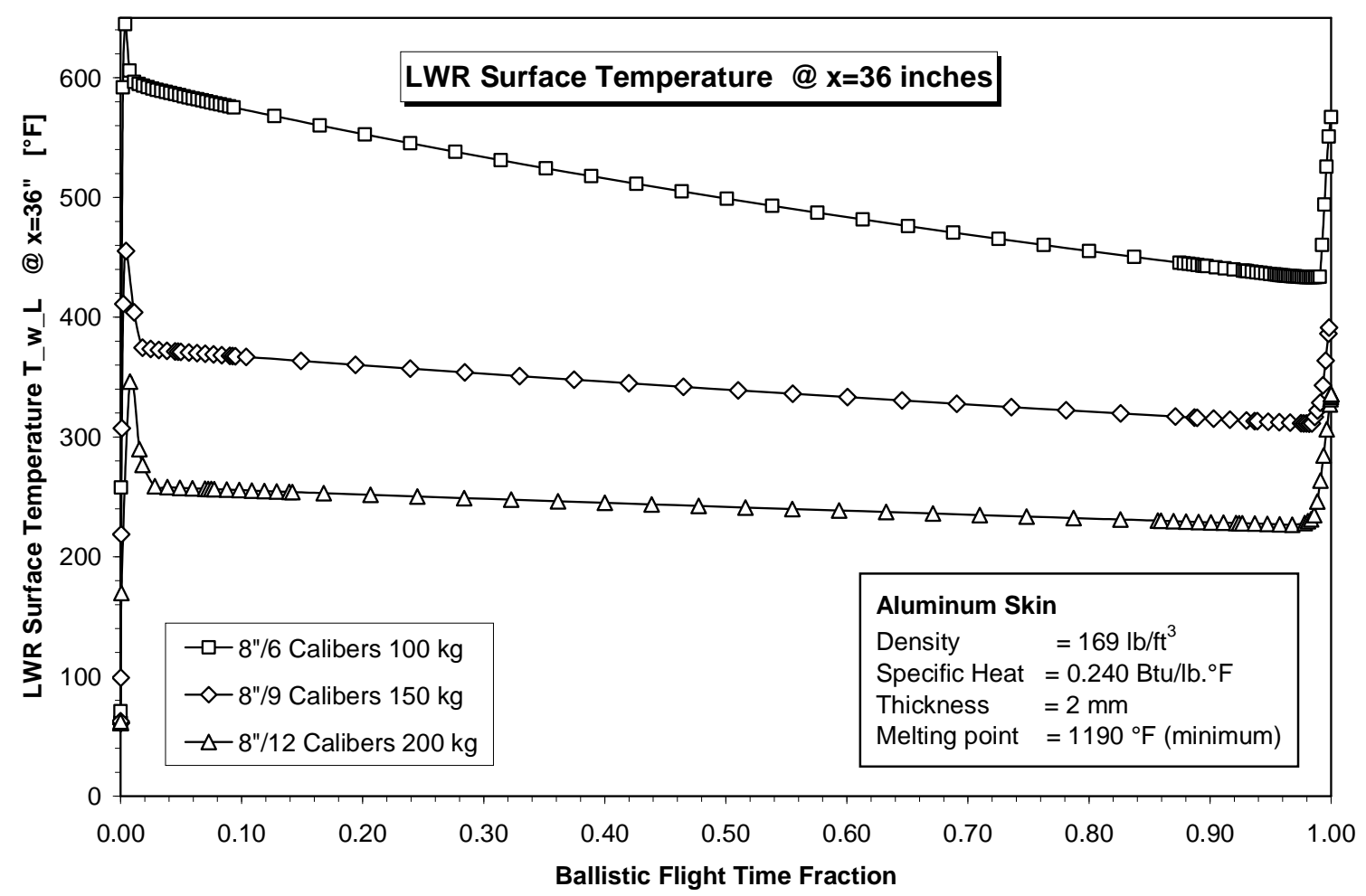

Figure 8: Comparison of the Lower Surface Temperatures at 36 inches from the Cone Tip

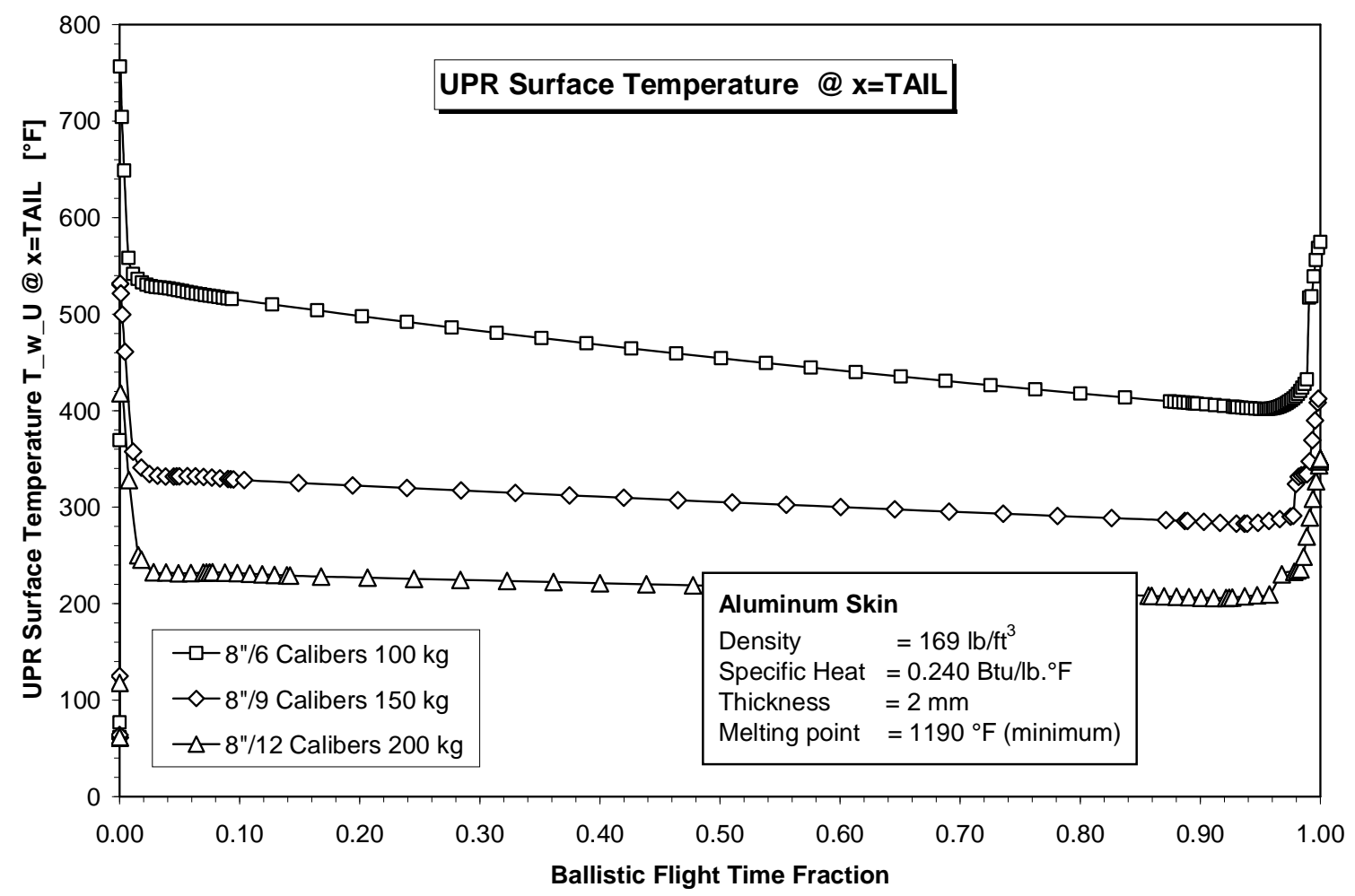

Figure 9: Comparison of the Upper Surface Temperatures at the Tail Points (These Points are at Different Distances from the Cone Tip) 


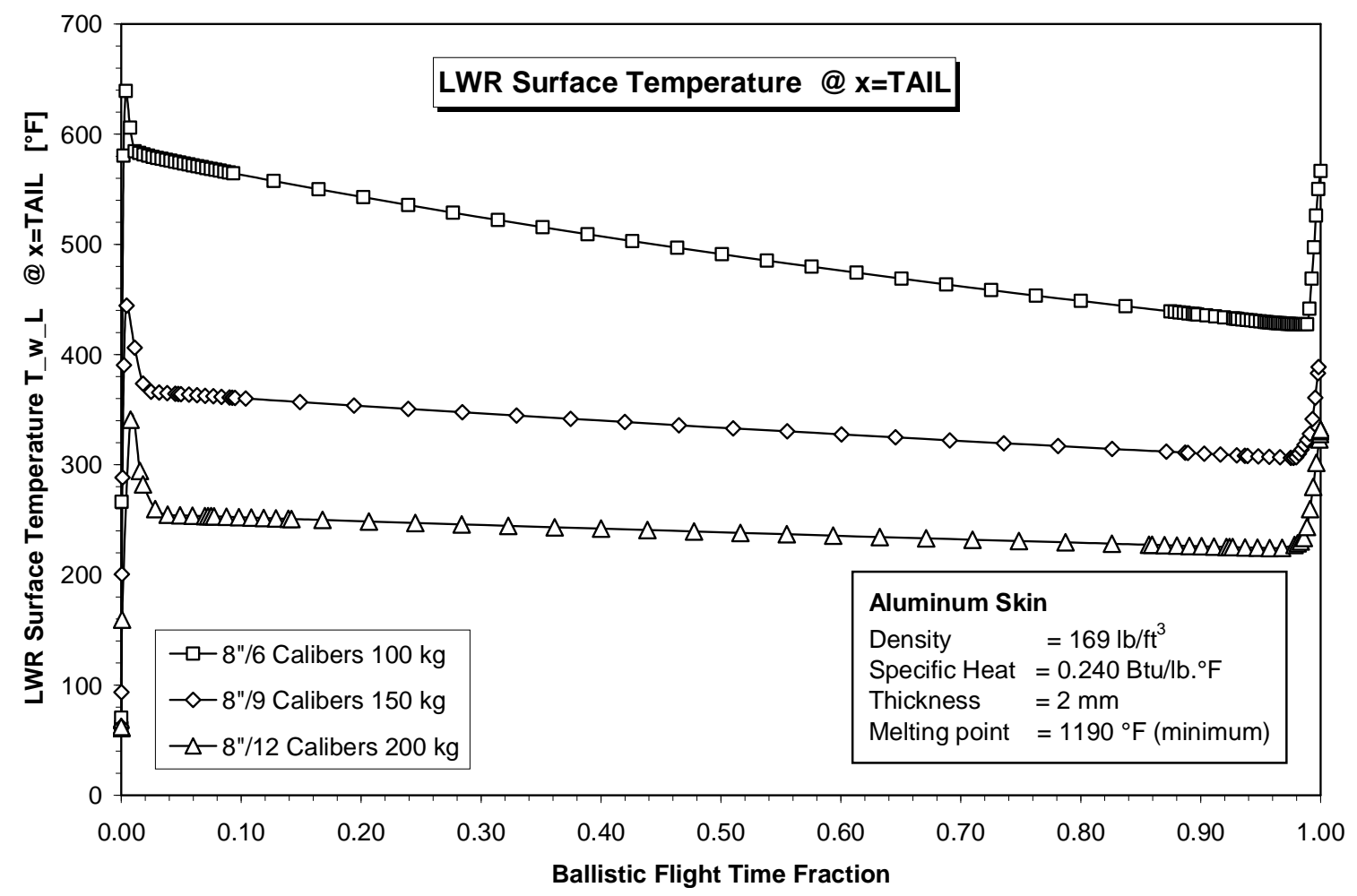

Figure 10: Comparison of the Lower Surface Temperatures at the Tail Points (These Points are at Different Distances from the Cone Tip)

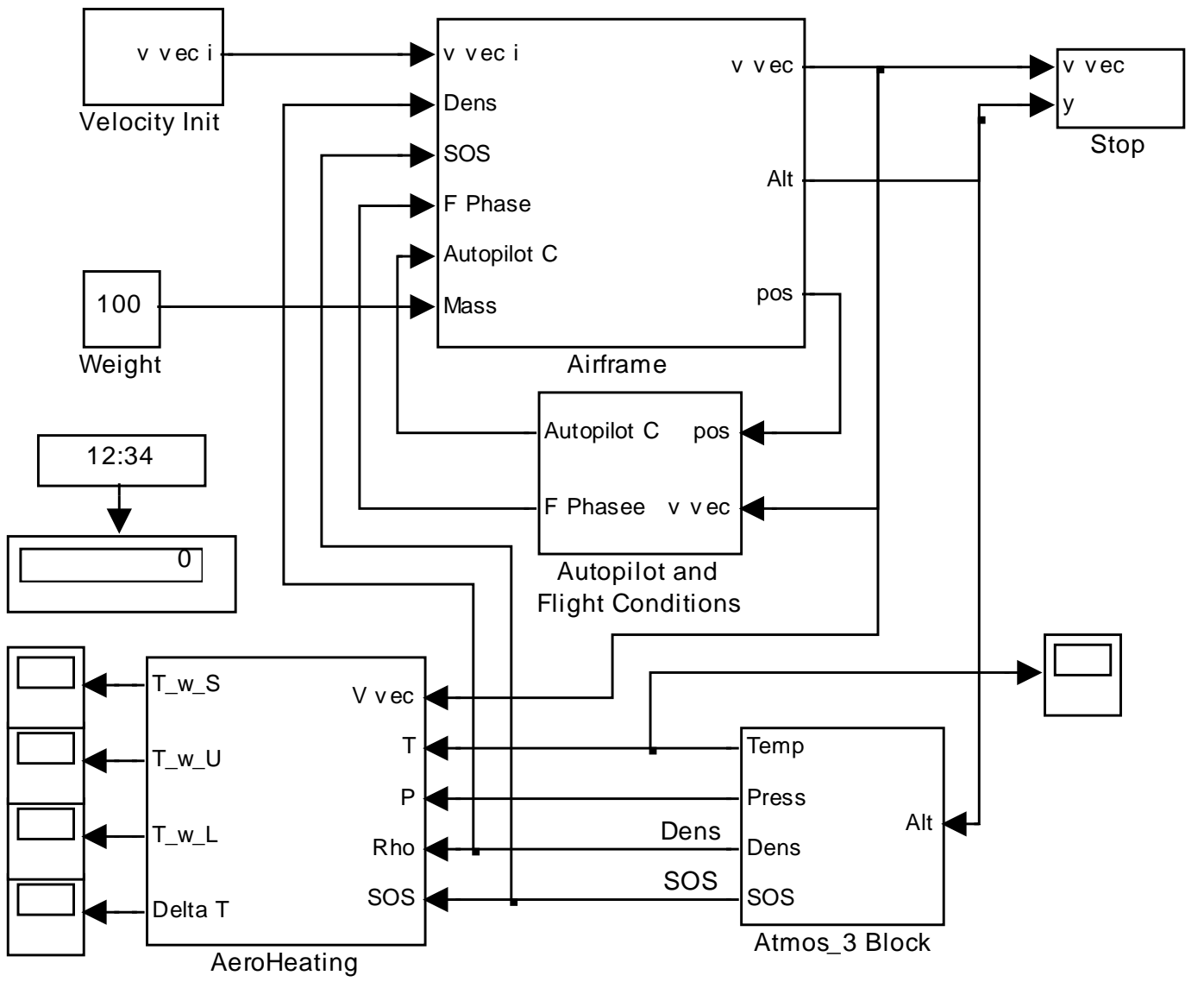

Figure 11: Outline of the Simulation Model

$10 / 16$ 


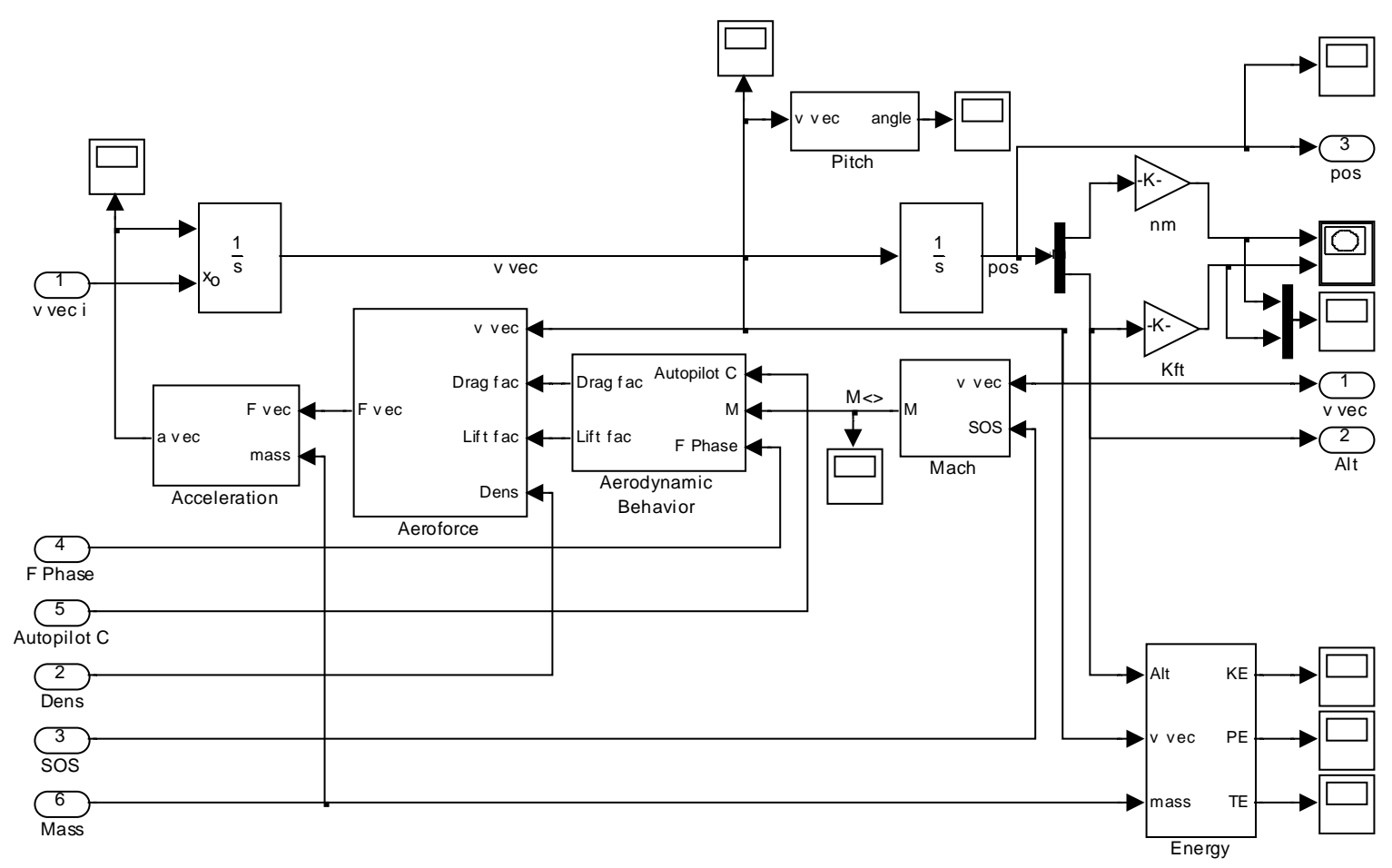

Figure 12: Outline of the Airframe Module Used to Simulate the 3DOF Exterior Ballistics Flight

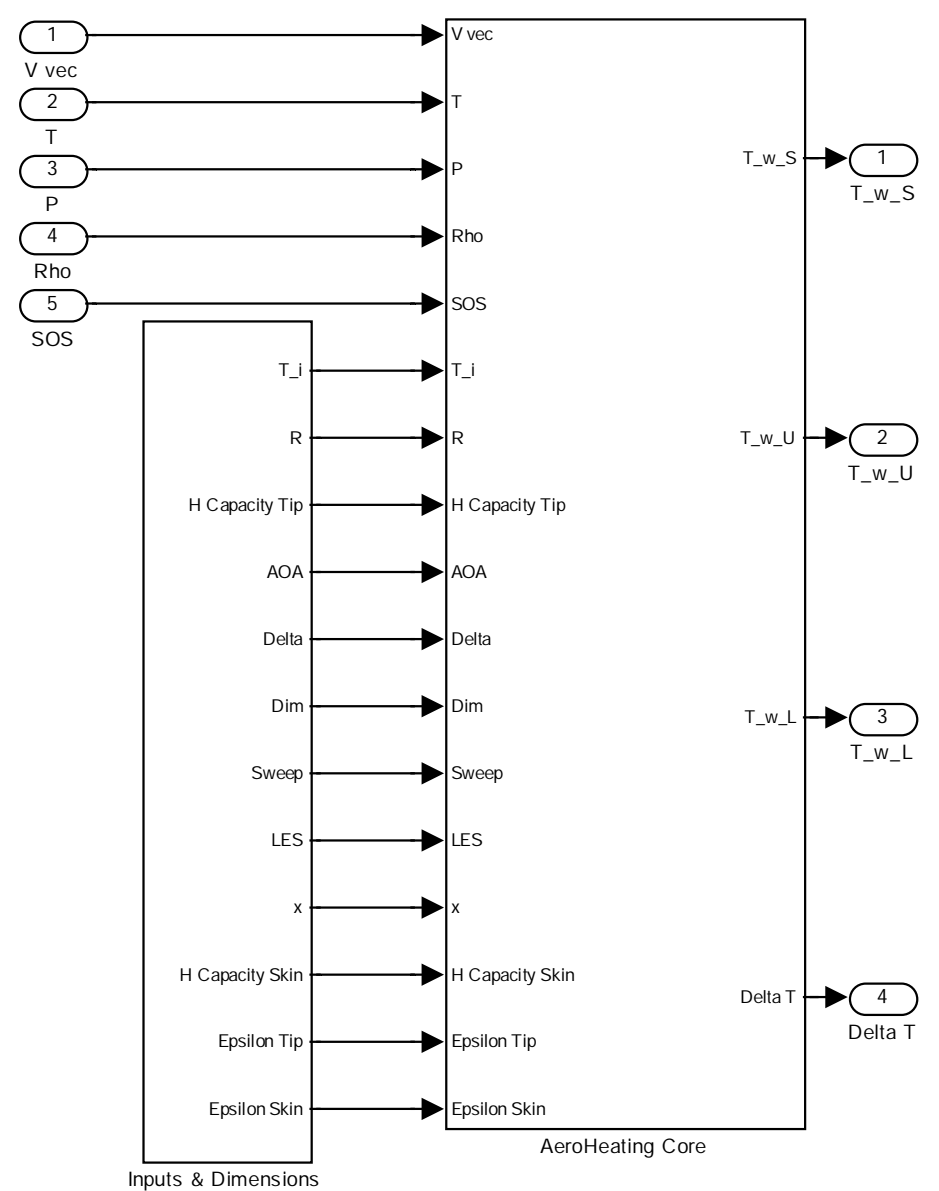

Figure 13: The Aerodynamic Heating Model 


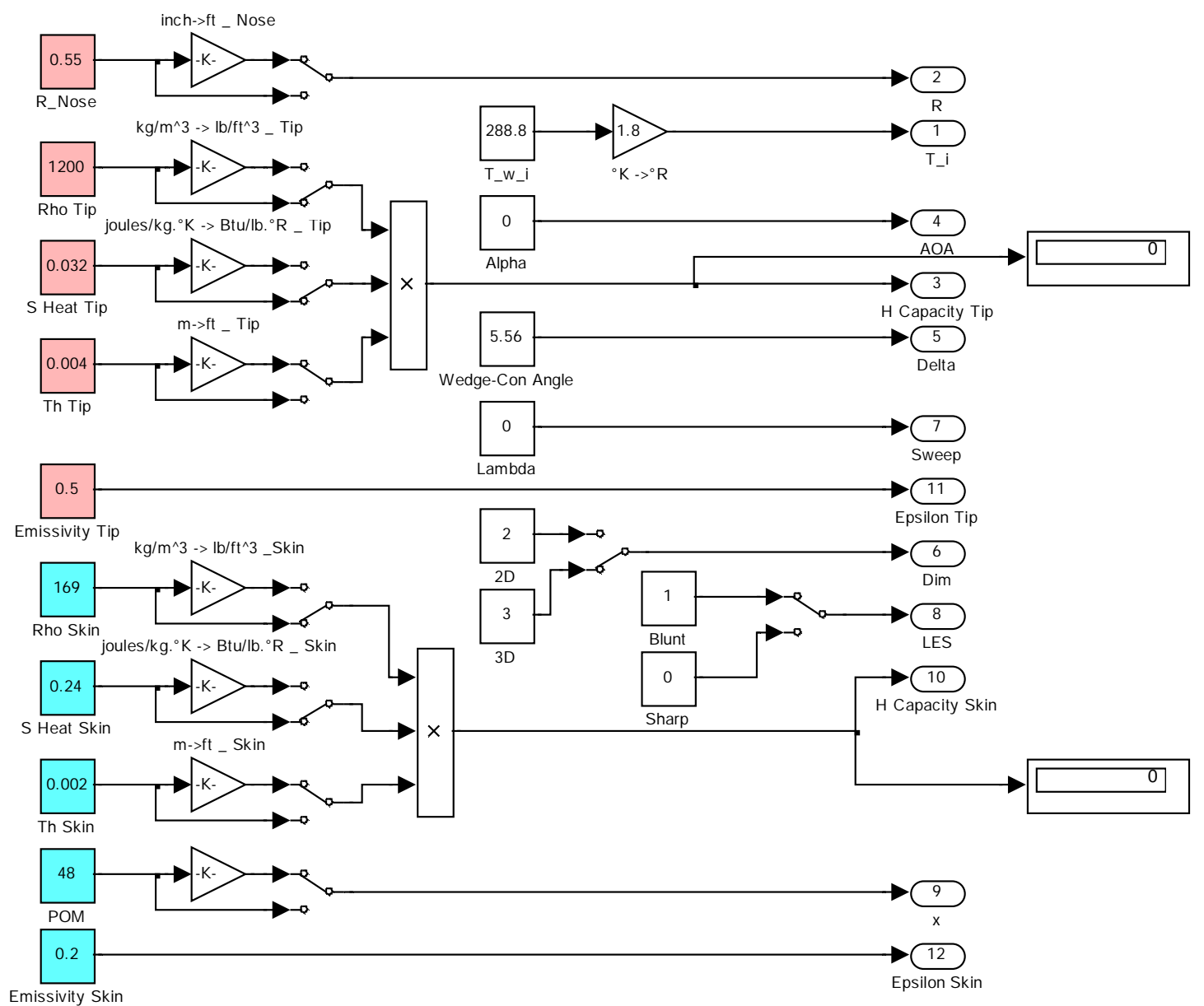

Figure 14: Inputs and Dimensions Module Used To Initialize the Model Using Either SI or English Units

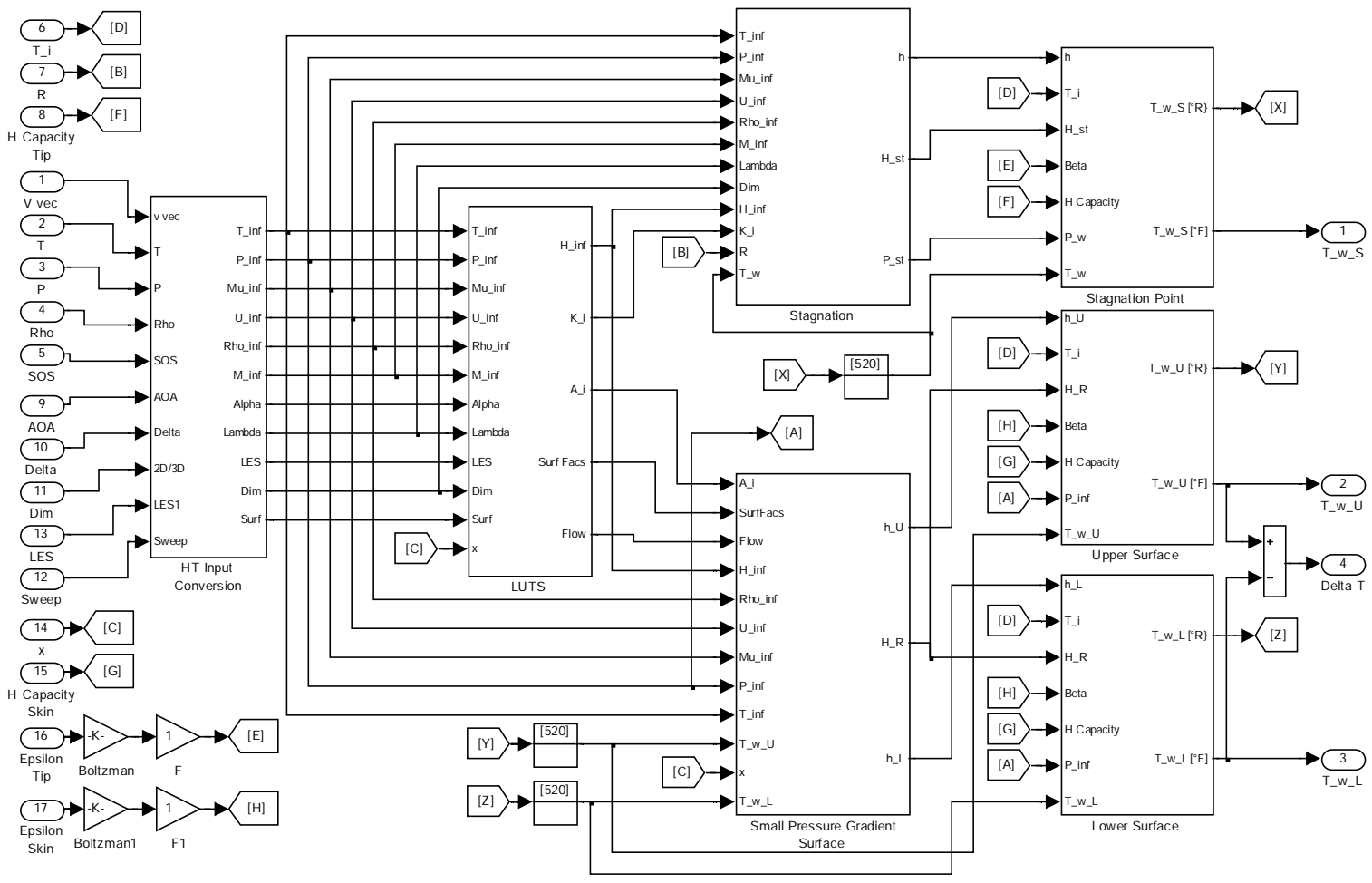

Figure 15: Elements of the Aerodynamic Heading Model 


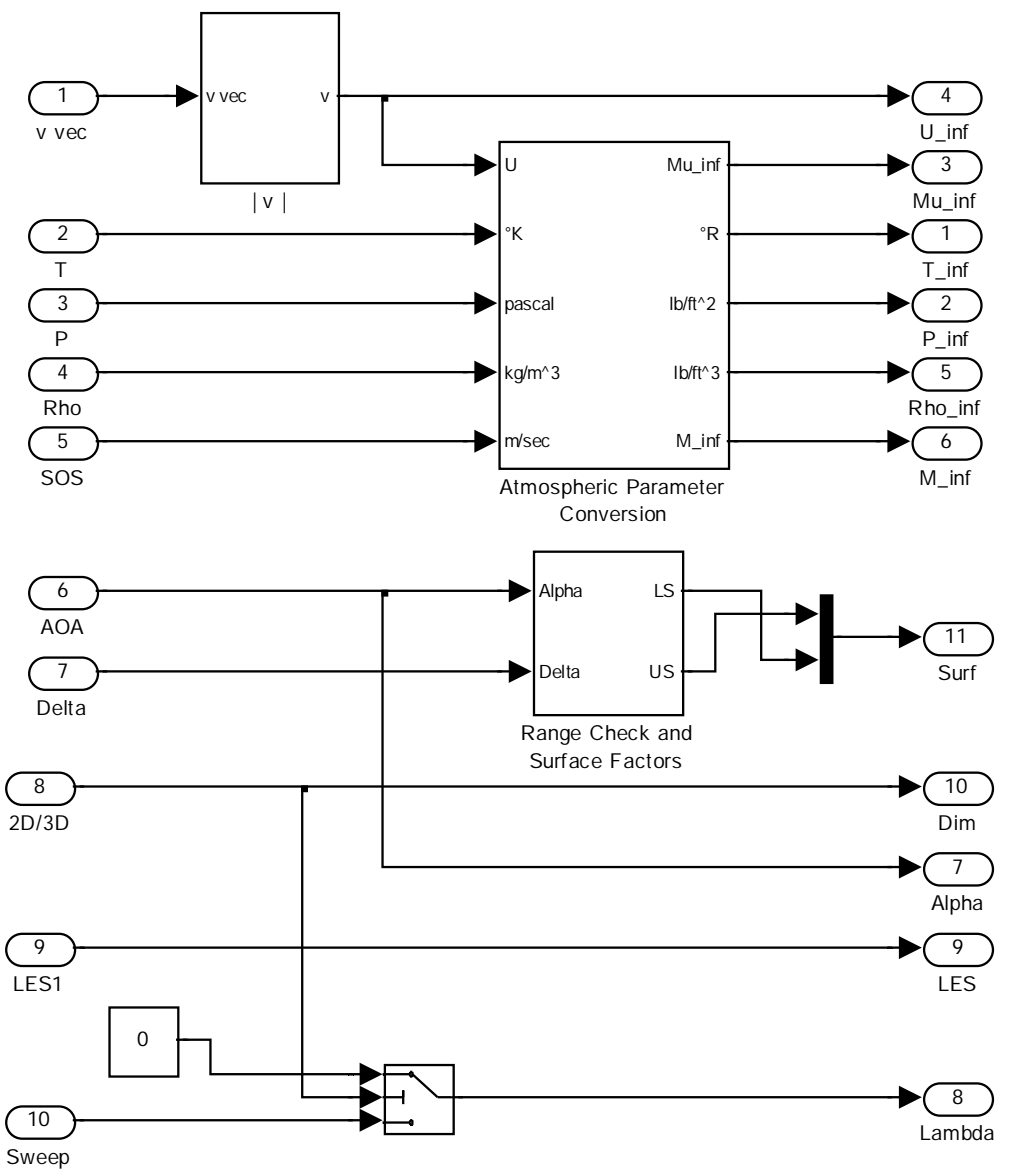

Figure 16: The HT Input Conversion Module

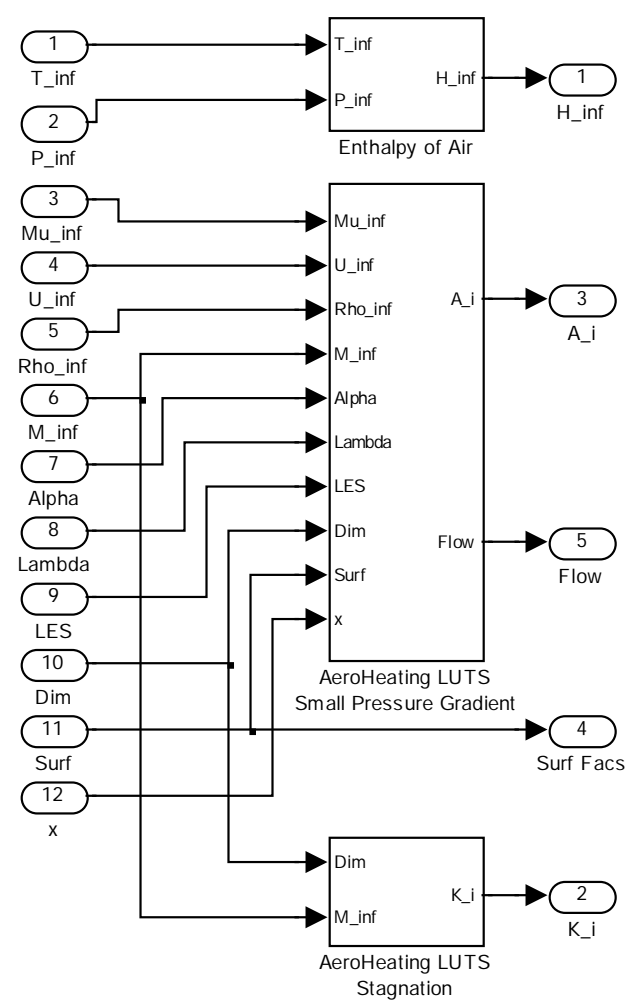

Figure 17: LUTS (Look Up Tables) and Its Subsystem Used To Determine Free Stream Enthalpy 


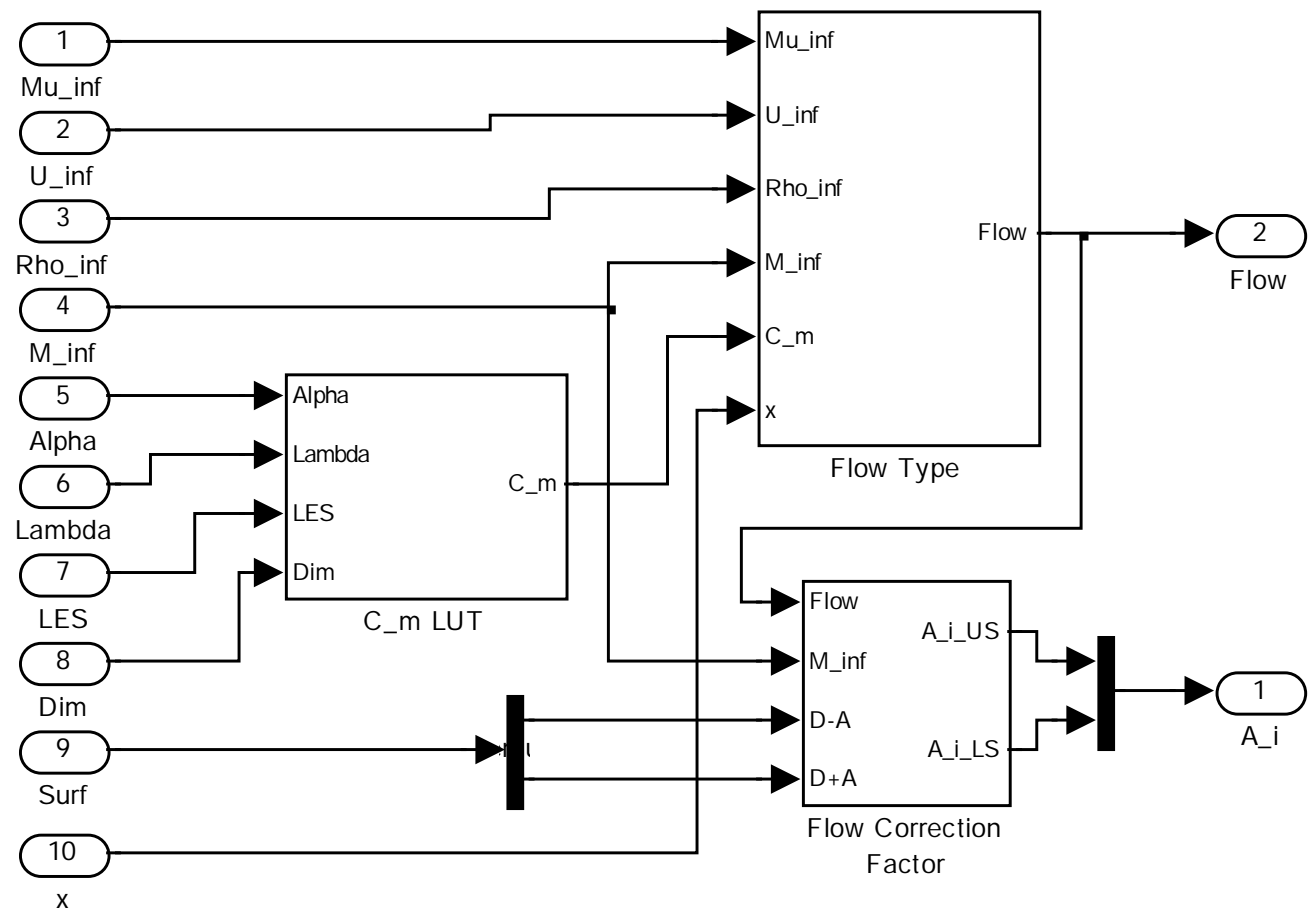

Figure 18: LUTS subsystems used to look up the Transition Mach number Coefficient (C_m), determine Flow Type, and look up the Flow Correction Factor (A_i)

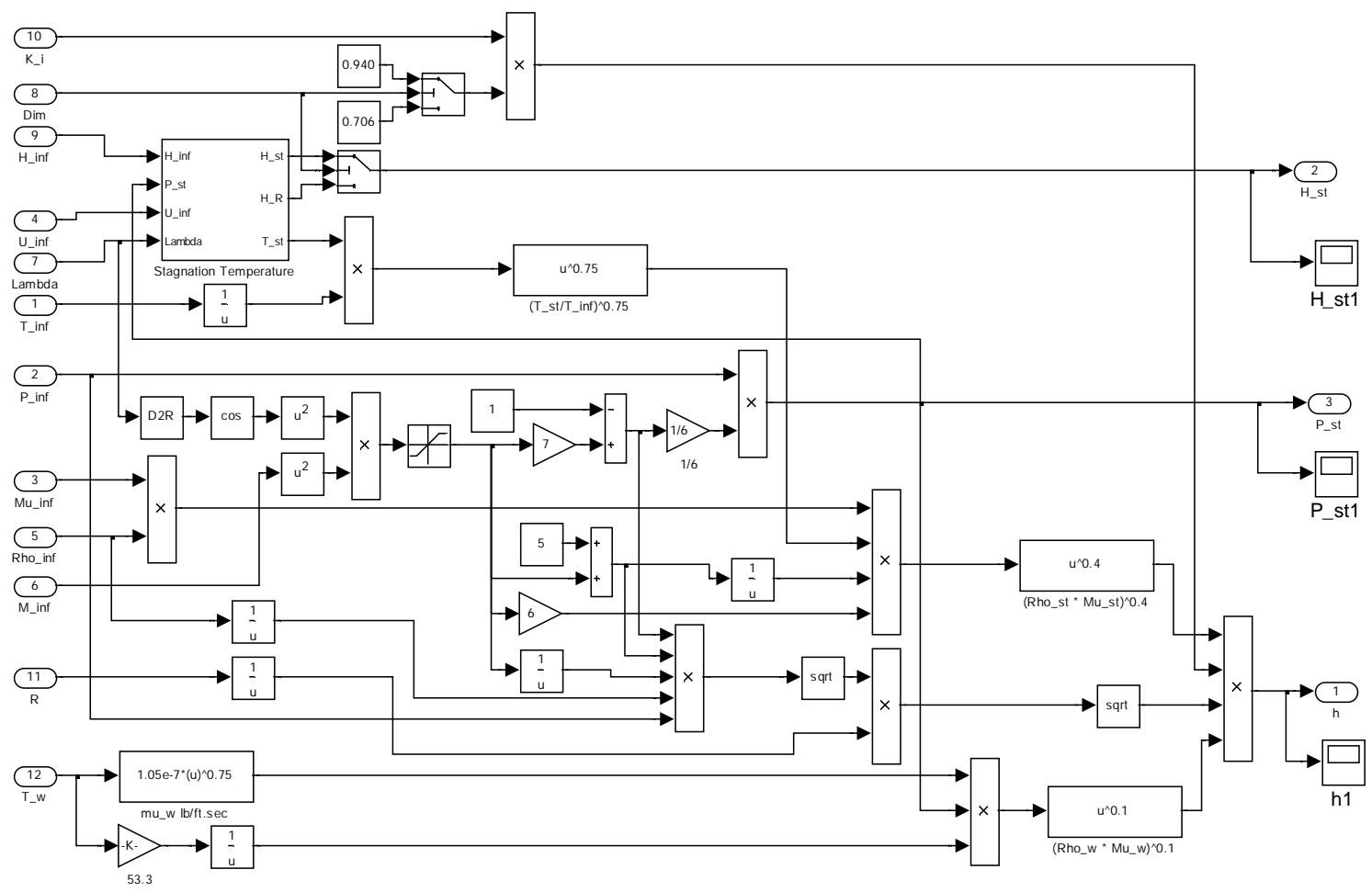

Figure 19: Stagnation Module used to compute the Stagnation Enthalpy (H_st), Stagnation Pressure (P_st), and Local Heat Transfer Factor (h) 


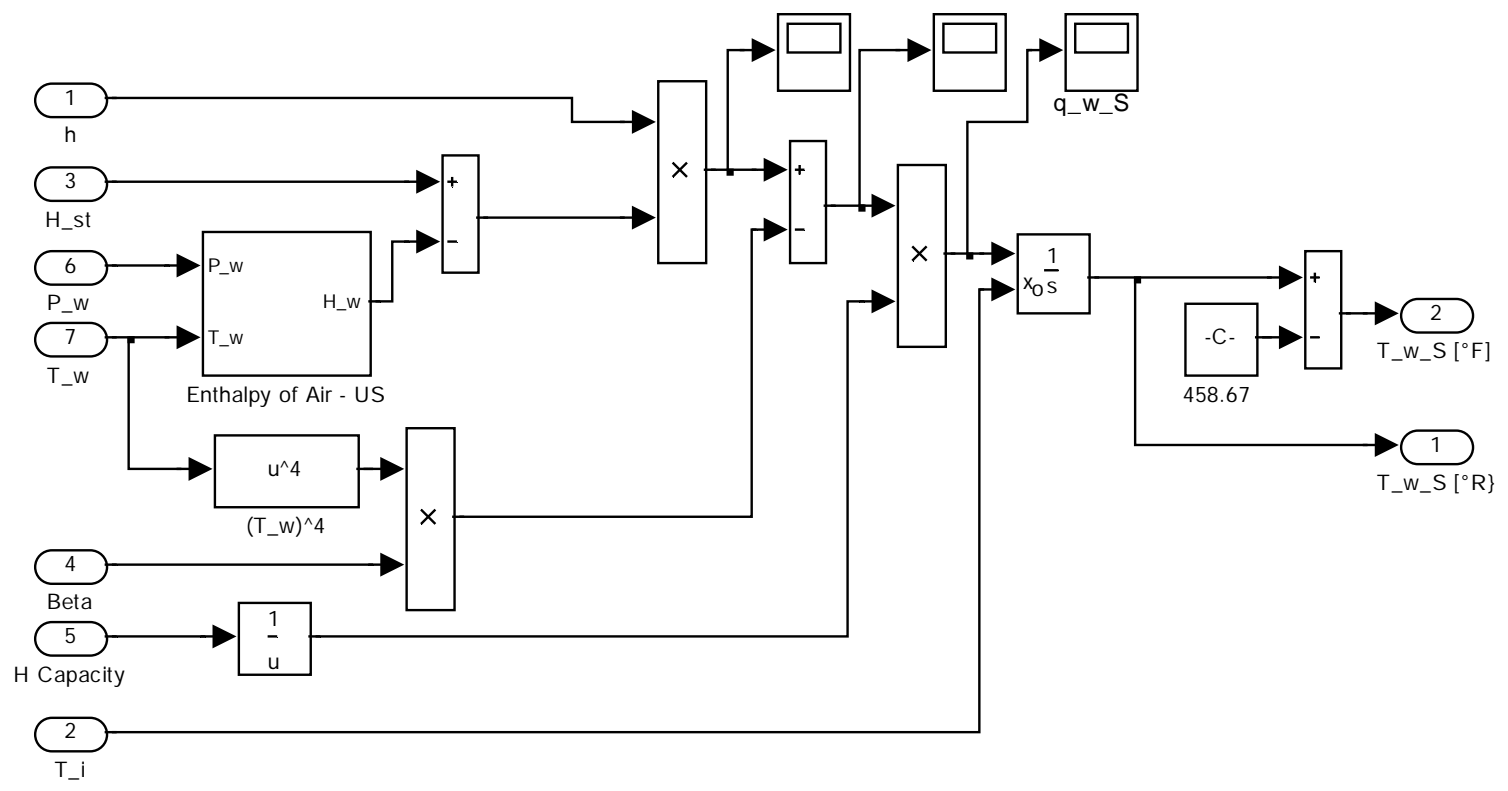

Figure 20: Stagnation Point module used to compute the Stagnation Temperature ( $\left.T_{-}{ }^{\prime} \_S\right)$ of the nose by integrating the heating rate

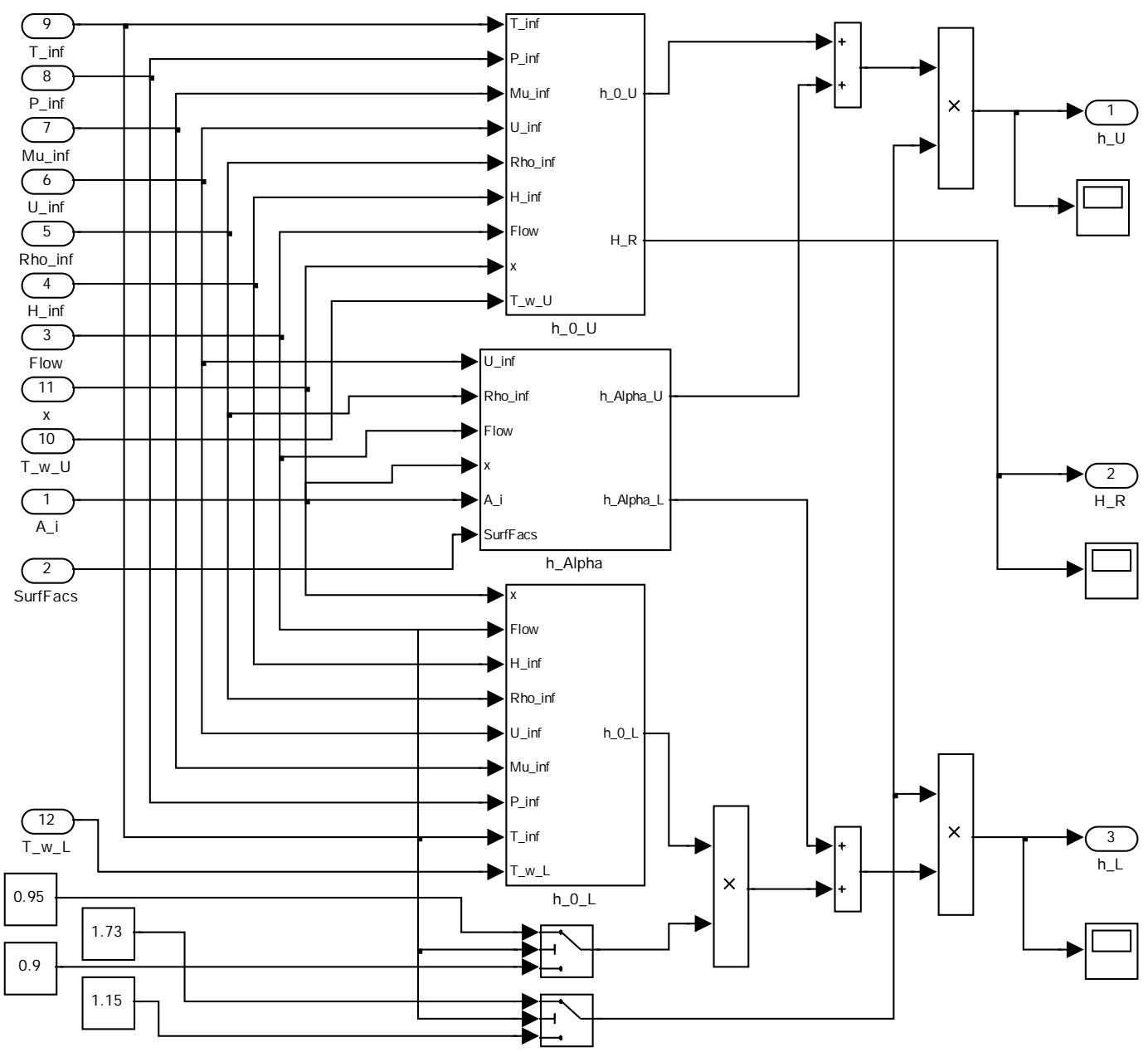

Figure 21: SPGS module used to compute the Reference Enthalpy $\left(H_{-}\right.$R) and the Local Heat Transfer Coefficients for the upper and lower surfaces $\left(h \_U\right)$ and $\left(h \_L\right)$ 


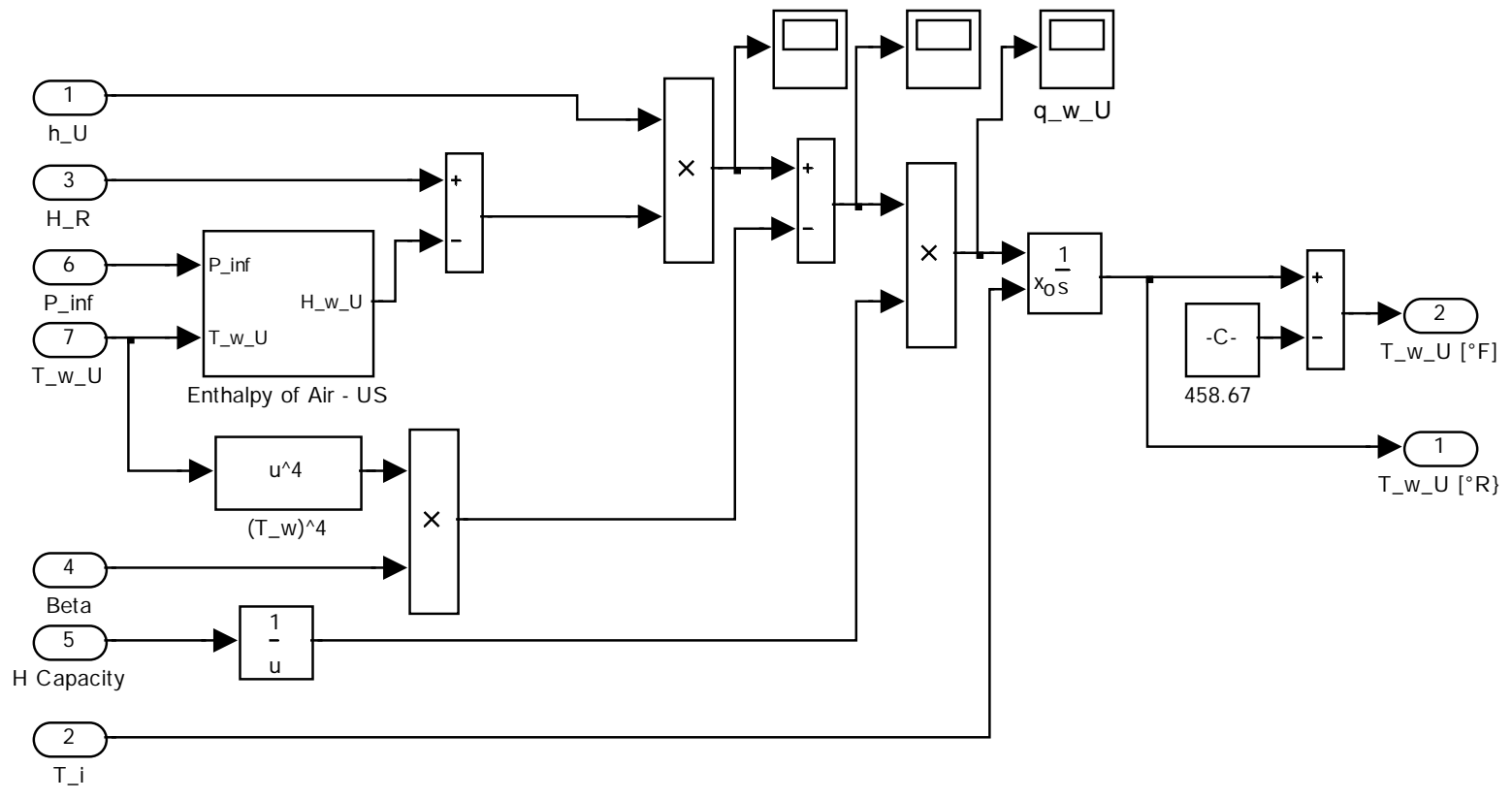

Figure 22: The Upper Surface (US) module used to compute the Upper Surface Temperature (T_w_U) at the point of measurement (POM) by integrating the heating rate at this point

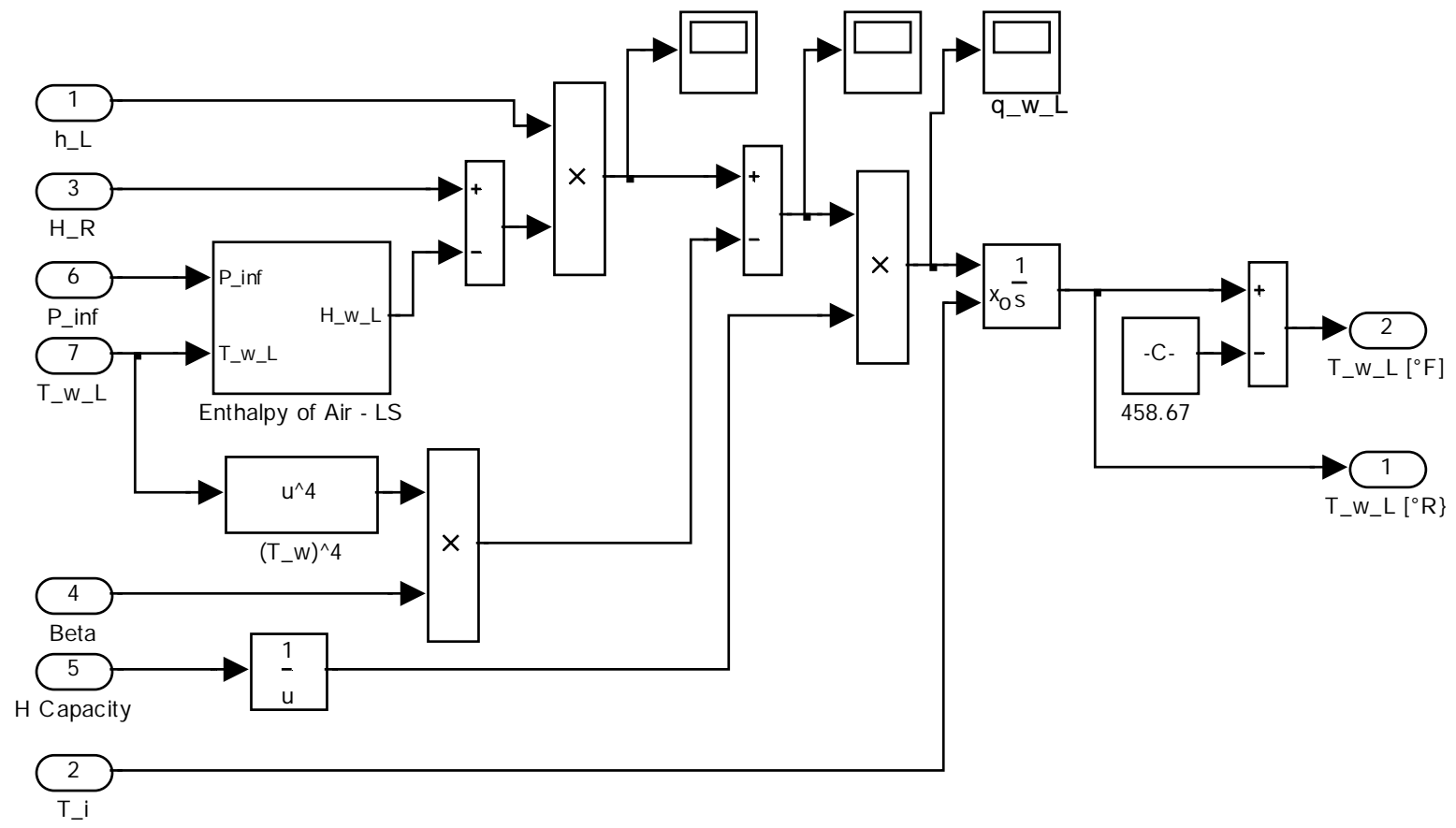

Figure 23: The Upper Surface (LS) module used to compute the Lower Surface Temperature (T_w_L) at the point of measurement (POM) by integrating the heating rate at this point 